\title{
Nitric Oxide Contributes to Estrogen-induced Vasodilation of the Ovine Uterine Circulation
}

\author{
Charles R. Rosenfeld, Blair E. Cox, Timothy Roy, and Ronald R. Magness \\ Department of Pediatrics, The University of Texas Southwestern Medical Center at Dallas, 5323 Harry Hines Blvd., Dallas, Texas 75235
}

\begin{abstract}
Estradiol-17 $\beta\left(E_{2} \beta\right)$, a potent vasodilator, has its greatest effects on the uterine vasculature, blood flow (UBF) increasing $\geq 10$-fold. The mechanism(s) responsible for $E_{2} \beta$-induced vasodilation is unclear. We determined if nitric oxide (NO)induced increases in cGMP modulate estrogen-induced increases in UBF, and if cyclooxygenase inhibition modifies $\mathrm{E}_{2} \beta$ responses. Nonpregnant $(n=15)$ and pregnant $(n=8)$ ewes had flow probes implanted on main uterine arteries and catheters in branches of the uterine vein and artery bilaterally for blood sampling and infusion of the NO synthase inhibitor L-nitro-arginine methyl ester (L-NAME), respectively. In nonpregnant ewes $\mathrm{E}_{2} \beta(1 \mu \mathrm{g} / \mathrm{kg})$ caused parallel increases $(P<0.001)$ in UBF $(15 \pm 3$ to $130 \pm 16 \mathrm{ml} /$ min) and uterine cGMP secretion ( $23 \pm 10$ to $291 \pm 38 \mathrm{pmol} /$ $\mathrm{min})$; uterine venous cGMP also rose $(4.98 \pm 1.4$ to $9.43 \pm 3.2$ $\mathrm{pmol} / \mathrm{ml} ; \boldsymbol{P}<0.001)$. Intra-arterial L-NAME partially inhibited increases in UBF dose-dependently $(r=0.66, n=18$, $P \leq 0.003)$ while completely inhibiting cGMP secretion $(P=$ $0.025)$. Indomethacin, $2 \mathrm{mg} / \mathrm{kg}$ intravenously, did not alter $E_{2} \beta$-induced responses. After $E_{2} \beta$-induced increases in UBF, intraarterial L-NAME partially decreased UBF dose dependently ( $r=0.73, n=46, P<0.001)$ while inhibiting cGMP secretion $(178 \pm 48$ to $50 \pm 24 \mathrm{pmol} / \mathrm{min} ; n=5, P=$ 0.006); both were reversed by L-arginine. In pregnant ewes, $\mathrm{E}_{2} \beta$ increased $\mathrm{UBF}$ and venous cGMP $(9.1 \pm 0.96$ to $13.2 \pm$ $0.96 \mathrm{pmol} / \mathrm{ml}, P<0.01)$; however, intraarterial L-NAME decreased basal cGMP secretion $66 \%(P=0.02)$, but not UBF. Acute estrogen-induced increases in UBF are associated with NO-dependent increases in cGMP synthesis, but other mechanisms may also be involved. However, vasodilating prostanoids do not appear to be important. In ovine pregnancy NO is not essential for maintaining uteroplacental vasodilation. (J. Clin. Invest. 1996. 98:2158-2166.) Key words: sheep • pregnancy $\bullet$ indomethacin $\bullet$ blood flow $\bullet$ cGMP
\end{abstract}

This paper was presented in part at Experimental Biology 95, 9-13 April 1995, Atlanta, GA.

Address correspondence to Charles R. Rosenfeld, UT Southwestern Medical Center at Dallas, 5323 Harry Hines Blvd., Dallas, TX 75235-9040. Phone: 214-648-3903; FAX: 214-648-2481. Dr. Magness' current address is Department of Obstetrics and Gynecology, University of Wisconsin Medical School, Madison, WI 53706.

Received for publication 7 March 1996 and accepted in revised form 15 August 1996.

J. Clin. Invest.

(C) The American Society for Clinical Investigation, Inc. 0021-9738/96/11/2158/09 \$2.00

Volume 98, Number 9, November 1996, 2158-2166

\section{Introduction}

Estrogen has a multiplicity of effects, which include vascular and nonvascular responses. Estrogen replacement decreases the incidence of cardiovascular disease in postmenopausal women (1), which has resulted in an intense interest in defining its effects on the cardiovascular system of women (2). Markee $(3,4)$ first demonstrated that estrogen might be a potent vasodilator of the uterine tissues. However, it was not until the studies of Killam et al. (5), using chronically instrumented nonpregnant ewes studied remote from surgery and anesthesia, that the magnitude of these effects on the uterine vascular bed were clearly demonstrated, uterine blood flow (UBF) ${ }^{1}$ increasing $>10$-fold after $1 \mu \mathrm{g} / \mathrm{kg}$ of intravenous (iv) estradiol-17 $\beta$ $\left(E_{2} \beta\right)$ rather than the $50-100 \%$ previously reported $(4,6,7)$. Rosenfeld et al. $(4,8,9)$, using the microsphere technique for measuring regional blood flows, not only confirmed these observations, but also demonstrated that $\mathrm{E}_{2} \beta$ had significant vasodilatory effects on several nonreproductive as well as reproductive tissues in nonpregnant, pregnant, and postpartum sheep and increased cardiac output $15-20 \%$, thereby demonstrating substantial systemic responses. Importantly, the uterine responses to $E_{2} \beta$ are locally mediated and independent of its effects on systemic vascular resistance $(5,10,11)$. Similar vasodilatory effects of estrogen also occur in women (12), and more recently, using doppler flow technology, uterine vascular resistance has been shown to fall during estrogen treatment (13). Thus estrogen responses in women and sheep are very similar.

Although estrogen has substantial effects on cardiovascular dynamics in several species, the mechanism(s) whereby this occurs remains unclear. Since the uterine vascular bed of nonpregnant ewes can be studied in relative isolation from the systemic vasculature $(5,10,11)$, this is an excellent model in which to study these mechanisms in intact animals. Several agents infused directly into the uterine circulation cause vasodilation; however, none result in either the pattern of response or the persistence in vasodilation seen with $E_{2} \beta$ (4). In in vivo studies there is a reproducible 30-min delay in both uterine and systemic responses to $\mathrm{E}_{2} \beta$ followed by a plateau after 90-100 min and a gradual decline over $8-12 \mathrm{~h}(4,5,10)$, thus the synthesis of new protein appears to be involved. This is supported by the observation that uterine responses to $E_{2} \beta$ are inhibited in a reversible manner by cycloheximide (5). However, Resnik et al. (14) and Penny et al. (15) reported that although pretreatment with actinomycin D blocked RNA synthesis, uterine responses to estrogen were unaffected, suggesting that transcription is not an important aspect of this re-

1. Abbreviations used in this paper: $\mathrm{E}_{2} \beta$, estradiol-17 $\beta$; L-NAME, L-nitro-arginine methyl ester; MAP, mean arterial pressure; NO, nitric oxide; NOS, NO synthase; UBF, uterine blood flow. 
sponse to estrogen. Thus identification of the "protein(s)" or mechanisms responsible for the vasodilatory responses to estrogen have been an enigma.

Nitric oxide (NO) is a potent vasorelaxant via its stimulatory effects on smooth muscle guanylate cyclase and the production of cGMP (16). It is the product of a family of enzymes, the nitric oxide synthases (NOS). The endothelial isoform (type III) is constitutive and believed to be important in maintaining basal vascular tone (16). The inducible form (type II) may not be constitutively expressed, thus requiring induction by cytokines or endotoxins (16). Its expression can be induced in macrophages and vascular smooth muscle, and it may be important in responses to sepsis. In recent studies it has been suggested that estrogen may mediate its vascular effects through stimulation of endothelial NO synthesis (2, 17-20); however, most of these studies have provided only indirect evidence for this. Therefore, in the present studies we utilized the isolated uterine vascular bed in intact nonpregnant castrated ewes to determine if blood flow responses to infused $\mathrm{E}_{2} \beta$ are mediated by enhanced NO synthesis as evidenced by parallel increases in uterine cGMP secretion/production and if these responses are inhibited by local infusion of a specific NOS antagonist. Additionally we examined the effects of cyclooxygenase on estrogen-induced vasodilation. We also sought to determine if there were differences in uterine cGMP secretion during normal ovine pregnancy, if these were altered by NOS inhibition, and if estrogen-induced increases in pregnant sheep were also associated with an increase in uterine cGMP secretion.

\section{Methods}

Animal preparation. Nonpregnant $(n=15)$ and pregnant $(n=8)$ ewes of mixed Western breed were used in the present studies. The surgical procedures and preparations have been described in part (5, 10). In brief, each animal was fasted overnight, but allowed access to water. In the morning animals received intramuscular atropine sulfate, and a percutaneous jugular venous catheter was placed for infusion of anesthetic agents. Using intravenous ketamine hydrochloride and pentobarbital, nonpregnant animals were ovariectomized and 3.0-3.5 mm (ID) electromagnetic flow probes (Micron Instruments, Los Angeles, CA) were implanted around the middle uterine artery of each uterine horn proximal to the first bifurcation. Polyvinyl catheters containing heparinized saline $(100 \mathrm{U} / \mathrm{ml})$ were implanted retrograde into a distal branch of the uterine artery and vein of both uterine horns, 2.5 and $10-15 \mathrm{~cm}$, respectively, the latter with its tip in the main uterine vein draining the horn, and in a femoral artery and vein to the level of the descending aorta and abdominal vena cava, respectively. Pregnant animals underwent similar procedures at 115-118 d gestation $($ term $=145 \mathrm{~d})$, but the ovaries remained intact and $6.0-7.0 \mathrm{~mm}$ (ID) flow probes were used. Ewes were maintained in individual stalls postoperative and were given standard animal chow and water ad libitum. Nonpregnant animals received estrogen replacement $\left(\mathrm{E}_{2} \beta, 1 \mu \mathrm{g} / \mathrm{kg}\right.$ iv; Steraloids, Wilton, $\left.\mathrm{NH}\right)$ on alternate days, but not within $24 \mathrm{~h}$ before study. Animals were not studied until the seventh postoperative day, by which time uterine responses to infused $E_{2} \beta$ were maximum and reproducible $(5,8)$.

Experimental protocols: nonpregnant ewes. The $\mathrm{E}_{2} \beta$ was dissolved in sterile $95 \%$ ethanol and stored at $4^{\circ} \mathrm{C}$ as a stock concentration of $1 \mathrm{mg} / \mathrm{ml}$. This solution was further diluted to $100 \mu \mathrm{g} / \mathrm{ml}$ with $95 \%$ ethanol and allowed to reach room temperature before injection. Four protocols were used in the study of nonpregnant ewes. In the first we sought to determine the effects of $\mathrm{E}_{2} \beta$ on uterine cGMP secretion/ production and UBF. Continuous recordings of mean arterial pressure (MAP), heart rate, and UBF were initiated $30 \mathrm{~min}$ before infus- ing an intravenous dose of $\mathrm{E}_{2} \beta(1 \mu / \mathrm{kg})$ over 1 min, a dose shown to elicit a maximum uterine response and to result in plasma levels associated with parturition $(4,5)$. Blood samples were obtained simultaneously from a femoral arterial (representative of uterine arterial blood) and uterine venous catheter $30 \mathrm{~min}$ before and just prior to the infusion of $E_{2} \beta$, and again at 30,60, 90, and 120 min after $E_{2} \beta$. Five ewes were included in these studies.

We next examined the effect of L-Nitro-Arginine Methyl Ester (L-NAME; Sigma Chemical Co., St. Louis, MO), a specific antagonist of NO synthesis (16), infused directly into the uterine circulation via a uterine artery catheter before $\mathrm{E}_{2} \beta$ treatment to demonstrate the role of $\mathrm{NO}$ in the estrogen-mediated rise in UBF. In preliminary studies L-NAME was continuously infused with a constant infusion pump after a 30-min control period and maintained for $120 \mathrm{~min}$. Doses were estimated to result in concentrations in the uterine artery ranging from 0.05 to $1 \mathrm{mg} / \mathrm{ml}$ and were determined from the rate of L-NAME infused and baseline measurements of UBF $(\mathrm{mg} / \mathrm{min} \div \mathrm{ml} / \mathrm{min}$, respectively). This approach, however, did not inhibit either the rise in UBF or in uterine venous cGMP (see Results). Subsequent studies, therefore, were performed by infusing L-NAME over 10-min to provide a higher concentration over a shorter period and thus to rapidly saturate the NOS enzyme. In these experiments hemodynamic monitoring was performed as noted above. Uterine arterial and venous blood samples were obtained before L-NAME, prior to $\mathrm{E}_{2} \beta$, and at $120 \mathrm{~min}$ after $E_{2} \beta$. Five nonpregnant ewes were included in these studies and only one dose of L-NAME was studied each day.

In the third protocol we examined the effects of locally infused L-NAME on UBF after reaching maximum UBF values 100-120 min after $\mathrm{E}_{2} \beta(4,5,8)$ in order to examine the role of $\mathrm{NO}$ in maintaining the estrogen-induced increase in UBF. In these studies varying doses of L-NAME were infused over $1 \mathrm{~min}$ into one uterine artery catheter and the blood concentration in milligram/milliliter was estimated as described earlier; no more than one dose per uterine horn was studied each day. Hemodynamic measurements were as described, and blood samples were taken before $E_{2} \beta, 120$ min after $E_{2} \beta$ but before L-NAME, and again at 5 and $30 \mathrm{~min}$ after the local infusion of L-NAME. In three experiments we infused $\mathrm{D}$-arginine and $\mathrm{L}$-arginine $(18 \mathrm{mg}$; Sigma Chemical Co.) intraarterially after stabilization of the responses to L-NAME to demonstrate specificity of the inhibitory effects of NOS. Five ewes were included in these experiments.

In the fourth protocol used in nonpregnant sheep, we wished to determine if the inhibition of cyclooxygenase modified the uterine and systemic responses to systemically infused $E_{2} \beta$. Monitoring was performed as described earlier; however, after obtaining control hemodynamic measurements for $10 \mathrm{~min}$, either vehicle or $2 \mathrm{mg} / \mathrm{kg}$ of sodium indomethacin (Merck Sharp \& Dohme, West Point, PA) was infused via the femoral venous catheter over $5 \mathrm{~min}$. This dose has been shown in previous studies to provide maximum inhibition of systemic cyclooxygenase activity $(21,22)$. 20 min after the indomethacin infusion $\mathrm{E}_{2} \beta$ was infused as noted above. In these studies we also measured cardiac output before and $20 \mathrm{~min}$ after indomethacin, before $\mathrm{E}_{2} \beta$, and at 90 and 120 min after $\mathrm{E}_{2} \beta$, using the dye-dilution technique previously validated in these laboratories (23). Four nonpregnant ewes were included in these studies.

Experimental protocols: pregnant ewes. In the studies of pregnant ewes (120-139 d gestation) we determined the plasma levels of cGMP in arterial and uterine venous blood as well as the uterine secretion of cGMP and compared these data with values obtained in nonpregnant animals. We also investigated the effects of local L-NAME infusions on basal UBF and/or uteroplacental cGMP secretion. As in the studies described above, L-NAME was infused intraarterially over $2 \mathrm{~min}$ to achieve blood levels ranging from 0.5 to $25 \mathrm{mg} / \mathrm{ml}$ as determined from basal UBF. Blood samples were taken from the uterine arterial and venous catheters before and 5 and $30 \mathrm{~min}$ after infusion while monitoring UBF, MAP, and heart rate. Since $\mathrm{E}_{2} \beta$ increases uteroplacental blood flow in pregnant ewes $(4,9)$, we also determined its effects $(1 \mu \mathrm{g} / \mathrm{kg})$ on uterine cGMP. The studies of $\mathrm{E}_{2} \beta$ were similar to those performed in the nonpregnant animals except that blood sam- 
ples were only obtained before and 120 min after estrogen infusion, and the effects of L-NAME were not investigated.

The studies described were approved by the Institutional Review Committee for Animal Research at The University of Texas Southwestern Medical Center at Dallas.

Hemodynamic measurements. MAP in the lower abdominal aorta was monitored continuously via a femoral arterial catheter connected to a pressure transducer (type 4-327-0109, Bell and Howell, Pasadena, CA). Heart rate was determined from the phasic signal derived from the arterial pressure monitor. UBF was monitored continuously with square-wave electromagnetic flowmeters (RC-1000; Micron Instruments, Los Angeles, CA). All measurements were continuously recorded on a six-channel pen recorder (3000; Gould, Inc., Cleveland, $\mathrm{OH}$ ).

Assays. Blood samples for measurements of cGMP were collected in chilled heparinized syringes, immediately centrifuged, and the plasma added to an equal volume of trichloroacetic acid (10\%). The samples were frozen on dry ice and stored at $-20^{\circ} \mathrm{C}$ until assayed. Plasma cGMP was measured by radioimmunoassay using a kit (New England Nuclear, Boston, MA) after saturated ether extraction $(\times 3)$. Briefly, the acidified plasma was centrifuged to remove protein and the TCA was then extracted from the resultant supernatant with saturated dimethyl ether $(\times 3)$ as described previously $(24)$.

Statistical analysis. ANOVA was used to examine changes over time. When significance was observed, Student-Newman-Keuls was used to determine differences between groups at $P<0.05$. Regres-
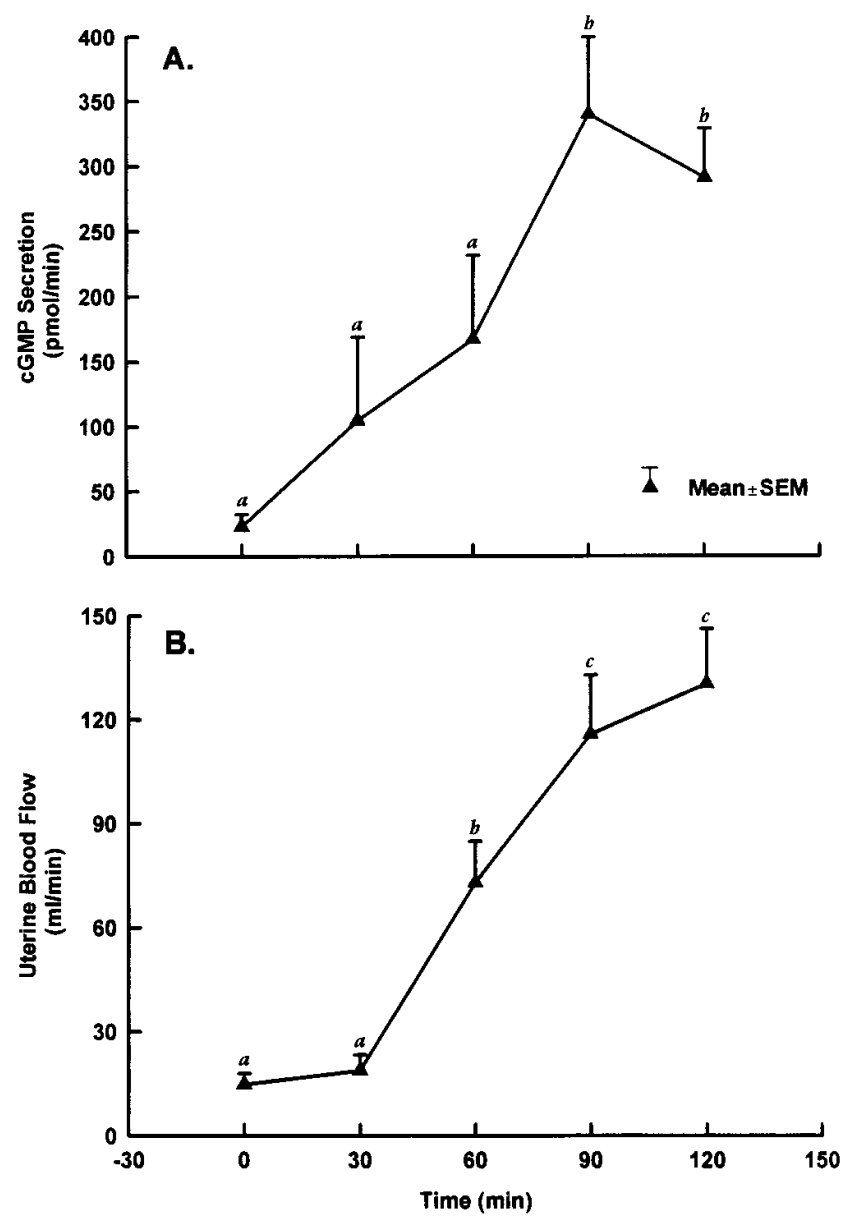

Figure 1. Pattern of change in uterine secretion of cGMP $(A)$ and uterine blood flow $(B)$ after the systemic intravenous infusion of 1 $\mu \mathrm{g} / \mathrm{kg} \mathrm{E} \mathrm{E}_{2} \beta(n=7)$ in nonpregnant sheep. Different letters denote differences between time periods at $P<0.001$ by ANOVA. sion analysis by the least squares method was used to determine changes across doses and to assess associations between variables. Values are presented as the mean and one SEM.

\section{Results}

Effects of $E_{2} \beta$ alone in nonpregnant ewes. In initial studies systemic infusion of $E_{2} \beta(1 \mu \mathrm{g} / \mathrm{kg})$ in nonpregnant ewes increased UBF from $23.4 \pm 5.0$ to $122 \pm 7.5 \mathrm{ml} / \mathrm{min}$ at $120 \mathrm{~min}$ and uterine venous cGMP from $6.71 \pm 1.1$ to $11.4 \pm 1.5 \mathrm{pmol} / \mathrm{ml}(n=14$, $P<0.02$ ). Therefore, serial blood samples were obtained in subsequent studies to determine the pattern of these responses as well as uterine secretion or production rate of cGMP. There was a time-dependent, progressive rise in both cGMP secretion (determined as the product of the venous-arterial concentration difference and UBF) and UBF (Fig. 1, $n=7, P<$ 0.001 ), values achieving a steady-state at $90-120 \mathrm{~min}$. It is notable that 30 min after $E_{2} \beta$ infusion the rise in cGMP secretion appears to exceed that of UBF, having increased 187 vs $24 \%$, respectively. Furthermore, uterine venous cGMP concentrations were significantly increased within $30 \mathrm{~min}$ after systemic $\mathrm{E}_{2} \beta(P<0.001)$, but were unchanged thereafter, values increasing $125 \%$ from $4.15 \pm 0.86$ to $9.43 \pm 3.2 \mathrm{pmol} / \mathrm{ml}$. In these experiments MAP was unchanged, averaging $88 \pm 2.6$ and $87 \pm 2.3 \mathrm{mmHg}$ at control and $120 \mathrm{~min}$, respectively, while heart rate rose from $73 \pm 4.5$ to $88 \pm 5.0(P<0.001)$, observations consistent with earlier reports (4). When all matched values were examined, the rise in UBF was linearly related to the level of uterine cGMP secretion: $\mathrm{UBF}(\mathrm{ml} / \mathrm{min})=29.8+0.221$ (cGMP, $\mathrm{pmol} / \mathrm{min}) ; r=0.68, n=35, P<0.001)$. Similar results were obtained when the relative increases were compared, $r=0.67, P<0.001$; however, the relative rise in cGMP secretion exceeded the rise in UBF at each time point.

Effects of $L-N A M E$ on $E_{2} \beta$ responses in nonpregnant ewes. Since the $E_{2} \beta$-induced increases in UBF were associated with increases in cGMP, we examined the effects of local NOS inhibition prior to $E_{2} \beta$ treatment and at the time of maximum UBF. When L-NAME $(0.05-1.0 \mathrm{mg} / \mathrm{ml}, n=5)$ was infused into the uterine artery before the systemic infusion of $\mathrm{E}_{2} \beta$ and the infusion maintained for $120 \mathrm{~min}$, there was no consistent inhibition of the rise in $\mathrm{UBF}$, uterine venous levels of cGMP or uterine secretion of cGMP, UBF rising from $10.2 \pm 3.0$ to $152 \pm 23 \mathrm{ml} / \mathrm{min}$. Subsequent studies, therefore, were performed using a 10-min intraarterial infusion of L-NAME before $E_{2} \beta$ treatment to rapidly saturate NOS with the inhibitor. With this regimen there was a dose-dependent inhibition of the $\mathrm{E}_{2} \beta$-induced rise in UBF (Fig 2; $P \leq 0.003$ ); however, even at an estimated arterial concentration of L-NAME of $10 \mathrm{mg} / \mathrm{ml}$ inhibition was only $\sim 70 \%$. In eight studies, simultaneous arterial and venous measurements of cGMP were available in the absence and presence of L-NAME infusion (Table I). In the absence of NOS inhibition there was a $\sim 10$-fold rise in UBF and cGMP secretion and 2-fold rise in uterine venous cGMP concentration 120 min after $\mathrm{E}_{2} \beta$ treatment. When L-NAME was locally infused before systemic $\mathrm{E}_{2} \beta$, using a dose estimated to inhibit the rise in $\mathrm{UBF}$ by $\sim 50 \%$, there was no significant effect of L-NAME on basal UBF or uterine venous cGMP concentration (Table I). However, the L-NAME pretreatment resulted in complete inhibition of the $\mathrm{E}_{2} \beta$-induced rise in uterine venous cGMP and cGMP secretion, and a $48 \%$ reduction in the rise in UBF, demonstrating a dissociation between the blood flow and cGMP responses. MAP was unchanged in the 


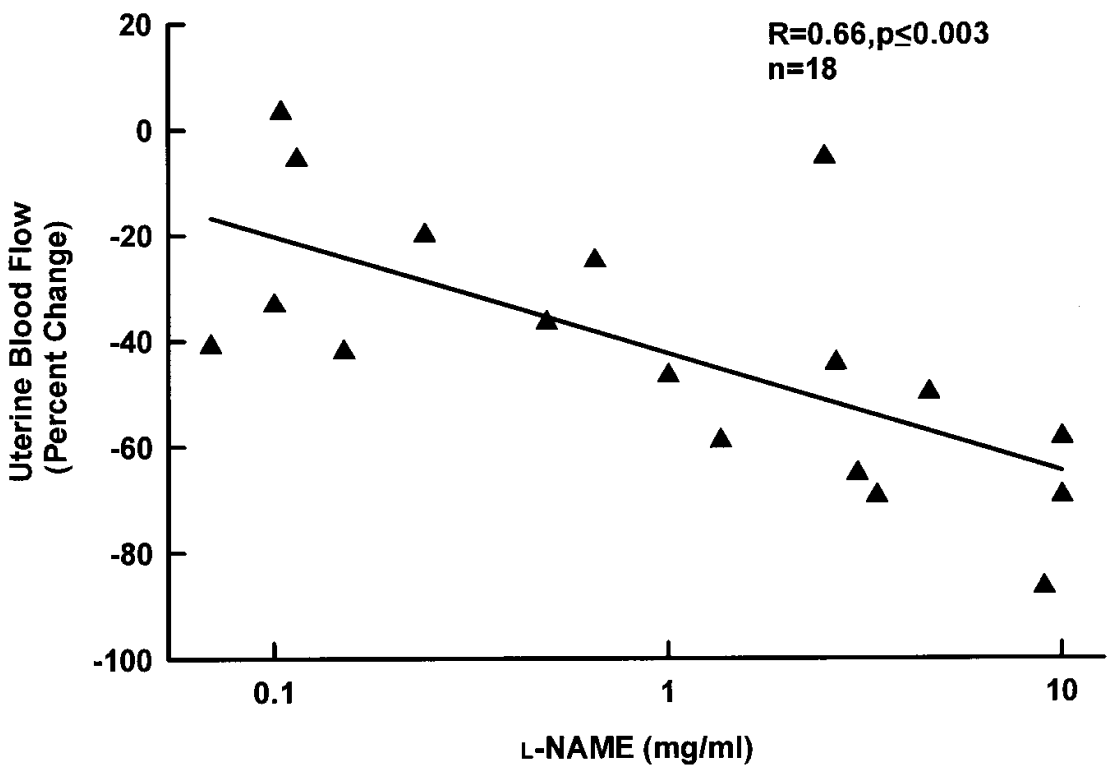

Figure 2. Relationship between the dose of L-NAME administered intraarterially before $\mathrm{E}_{2} \beta$ treatment in nonpregnant sheep and the percent inhibition of estrogen-induced increases in uterine blood flow.
L-NAME studies and heart rate rose from $61 \pm 2.4$ to $74 \pm 3.4$ beats per minute $(P=0.02)$, demonstrating intact systemic responses.

To determine if continued NO synthesis and cGMP are involved in maintaining $\mathrm{E}_{2} \beta$-induced rises in UBF, L-NAME was infused locally at the time of maximum UBF, i.e., 100-110 min post- $E_{2} \beta$. There was a dose- dependent fall in UBF (Fig. 3; $r=0.73, P<0.001)$ with estimated blood levels ranging from $<0.01$ to $10 \mathrm{mg} / \mathrm{ml}(n=46)$, and inhibition was maximum 5-7 min after the intraarterial infusion of L-NAME. However, as observed above, inhibition of the $\mathrm{E}_{2} \beta$-mediated increases in UBF was incomplete, averaging $\sim 70 \%$ at the highest dose of L-NAME. Paired arterial and venous blood samples for measurement of cGMP were available in five experiments in which the dose of L-NAME averaged $0.66 \mathrm{mg} / \mathrm{ml}$ (Fig. 4). As illustrated, UBF, decreased significantly within 5 min of L-NAME infusion, but did not return to baseline values. In contrast, cGMP secretion fell to values that did not differ from baseline (ANOVA). MAP was unaffected by local L-NAME infusions

Table I. Effects of Pre- $E_{2} \beta$ Intraarterial Infusions of $L-N A M E$ $(2.1 \pm 0.6 \mathrm{mg} / \mathrm{ml}, n=8)$ on $E_{2} \beta$-induced Increases in $U B F$, Uterine Venous Concentrations and Uterine cGMP Secretion of cGMP in Nonpregnant Ewes

\begin{tabular}{lccc}
\hline \multicolumn{1}{c}{ Time } & UBF & Venous cGMP & cGMP secretion \\
\hline & ml/min & pmol/ml & pmol/min \\
& & & \\
$(A) \mathrm{E}_{2} \beta$ alone $(n=7)$ & & & \\
Pre- $\mathrm{E}_{2} \beta$ & $14.8 \pm 3.2$ & $4.98 \pm 1.4$ & $22.9 \pm 9.5$ \\
$120 \mathrm{~min}$ & $130 \pm 16$ & $8.24 \pm 1.6$ & $291 \pm 38$ \\
$(B)$ Pre- $\mathrm{E}_{2} \beta$ L-NAME & & & \\
$(n=8)$ & & & \\
Pre-L-NAME & $15.5 \pm 2.4$ & $4.04 \pm 0.40$ & $20.1 \pm 5.3$ \\
Pre- $\mathrm{E}_{2} \beta$ & $14.8 \pm 2.8$ & $3.58 \pm 0.26$ & $-6.78 \pm 3.7$ \\
120 min & $66.5 \pm 4.9^{\ddagger}$ & $4.20 \pm 0.54^{*}$ & $-43.2 \pm 43^{\ddagger}$ \\
& & & \\
\hline
\end{tabular}

Values are mean \pm SEM. $* P=0.025$ and ${ }^{\ddagger} P \leq 0.001$ compared to $\mathrm{E}_{2} \beta$ alone.
$(P=0.17)$, whereas the rise in heart rate returned to pre- $\mathrm{E}_{2} \beta$ values $(P=0.002)$.

To demonstrate the specificity of the observed effects of L-NAME on NOS inhibition, we examined the effects of intraarterial infusions of $\mathrm{D}$-arginine and L-arginine, the substrate for NOS, on UBF after its inhibition with L-NAME (9 mg). While D-arginine ( $n=3,18 \mathrm{mg}$ infused over $1 \mathrm{~min})$ did not effect UBF (Fig. 5), the same dose of L-arginine $(n=3)$ caused an immediate rise in UBF to pre-L-NAME levels. Furthermore, uterine cGMP secretion, which had decreased from 274 to $29 \mathrm{pmol} / \mathrm{min} 30 \mathrm{~min}$ after L-NAME $(n=2)$, also returned to pre-L-NAME values after local infusion of L-arginine, $212 \mathrm{pmol} /$ min. In two other experiments the local infusion of L-arginine (60 and $80 \mathrm{mg}$ ) before $E_{2} \beta$ had no observed effect on UBF (data not shown).

Effects of indomethacin in nonpregnant ewes. Since cyclooxygenase products might play a role in the $\mathrm{E}_{2} \beta$-induced rise in UBF, we examined the effects of iv indomethacin $(2 \mathrm{mg} / \mathrm{kg})$ on hemodynamic variables before and after estrogen treatment. $\mathrm{E}_{2} \beta$ alone increased UBF 3.5 -fold, cardiac output $12 \%$, and a heart rate $13 \%$ (Table II), but MAP was unchanged, findings consistent with previous reports from this laboratory $(4,9,10)$. Indomethacin had no significant effect on basal UBF, cardiac output, or MAP, but was associated with a modest fall in heart rate (Table II), likely reflecting the transient rise in MAP that occurs immediately after indomethacin infusion but is gone within $20 \mathrm{~min}$ (21). There was no effect of indomethacin on the $E_{2} \beta$-induced increases in UBF, cardiac output or heart rate, and MAP was unaffected (Table II).

Studies of pregnant ewes. UBF increases $>30$-fold during ovine pregnancy, reflecting both growth and vasodilation of the vascular beds comprising the uteroplacental circulation (4). The mechanism(s) responsible for maintaining this vasodilatory state during pregnancy is not known. Thus we examined the relationship between UBF and uterine cGMP in pregnant ewes as well as the responses to local intraarterial infusions of L-NAME in the last third of gestation. As anticipated, UBF was significantly greater in pregnant sheep (Table III). Furthermore, the arterial and uterine venous concentra- 


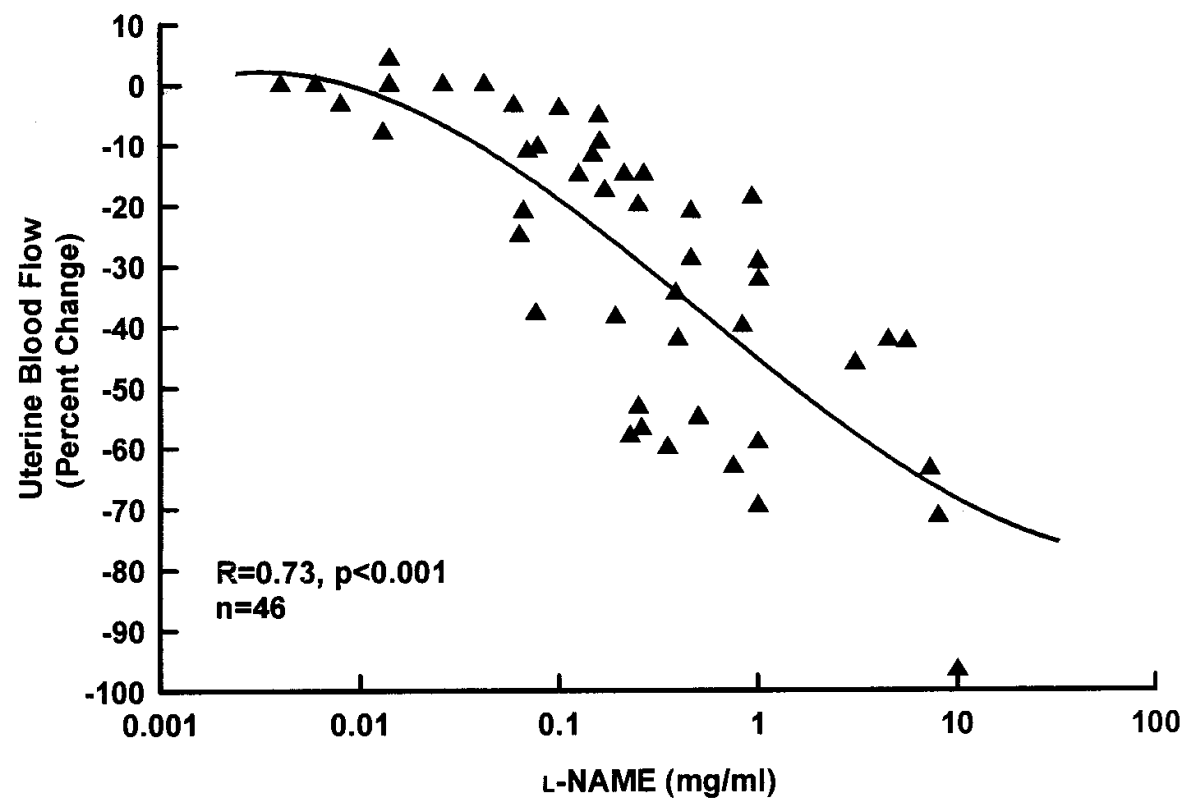

Figure 3. Dose-response curve depicting the relationship between the dose of L-NAME infused locally over $1 \mathrm{~min}$ and the percent change in uterine blood flow following the maximum response to the systemic infusion of $E_{2} \beta(1 \mu \mathrm{g} / \mathrm{kg})$ in nonpregnant sheep. tions of cGMP were $\geq 3$-fold greater than that of nonpregnant animals, resulting in a greater venous-arterial concentration difference and a 38-fold greater uterine cGMP secretion. When L-NAME was infused intraarterially the responses were extremely variable, and there was no evidence for a dose-dependent effect of L-NAME on UBF in either the gravid or nongravid uterine horn $(r=0.25, P=0.11, n=42)$. When we examined the effect of L-NAME on UBF 5 min after the local infusion of doses $>1 \mathrm{mg} / \mathrm{ml}$ (four of seven doses lower than this had no effect), UBF decreased $26 \pm 4.2 \%(n=35)$, but this was not significant, $P=0.08$. Similar observations were made at 10 and $30 \mathrm{~min}, P>0.1$. In five experiments we were able to obtain simultaneous arterial and uterine venous blood samples for measurement of cGMP before and after local treatment with L-NAME $(12 \pm 6 \mathrm{mg} / \mathrm{ml}$; Table IV). Although UBF was unchanged, uterine cGMP secretion fell $\sim 66 \%(P=0.02)$.

In seven experiments performed in three pregnant ewes simultaneous measurements of plasma cGMP and UBF were obtained before and after systemic infusions of $E_{2} \beta(1 \mu \mathrm{g} / \mathrm{kg})$. As expected (9), UBF rose $42 \%(P=0.07)$, increasing from $324 \pm 86$ to $459 \pm 102 \mathrm{ml} / \mathrm{min}$. Uterine venous cGMP rose $22 \%$
$(13.4 \pm 1.3$ to $16.4 \pm 1.6 \mathrm{pmol} / \mathrm{ml}, P<0.02)$ and arterial cGMP rose $45 \%$ (9.1 \pm 0.96 to $13.2 \pm 0.96 \mathrm{pmol} / \mathrm{ml}, P<0.01)$. Because the rise in systemic arterial cGMP exceeded that in uterine venous cGMP, there was no significant change in uterine cGMP secretion, thus demonstrating the overall systemic effects of $E_{2} \beta$ on cGMP.

\section{Discussion}

Estrogen is a potent vasodilator of the uterine and systemic vasculature of nonpregnant and pregnant ewes (4-11) as well as women $(12,13)$. It has been suggested that the mechanisms responsible for this vasodilation are difficult to assess and study in intact animals because of the potential for systemic effects. We (10), however, have demonstrated in nonpregnant ewes that although the patterns of the uterine and systemic responses to estrogen are identical, they occur independently of each other; thus the uterine responses after systemic $\mathrm{E}_{2} \beta$ infusion reflect the local direct effects of estrogen. Furthermore, this model permits not only the measurement of uterine arterio-venous concentration differences for various substances

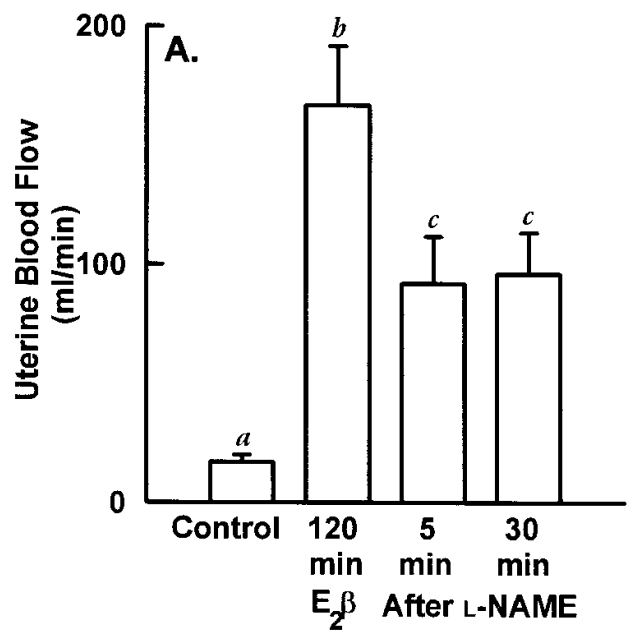

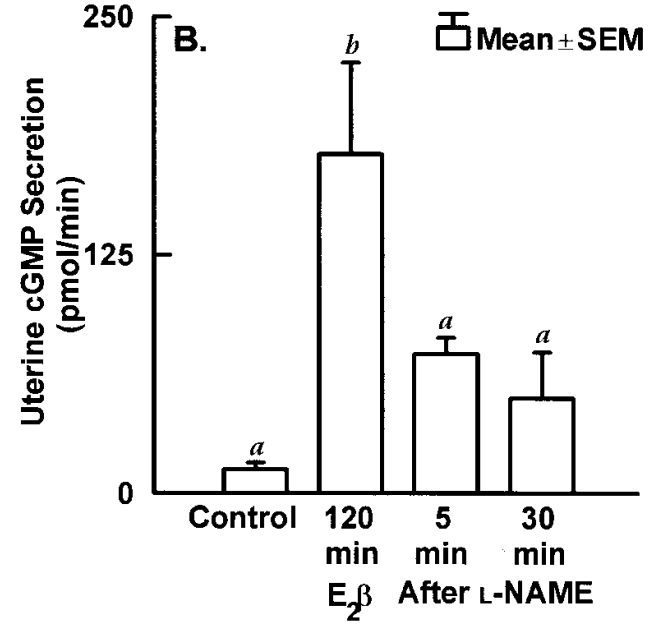

Figure 4. The effect of intraarterial infusions of L-NAME $(n=$ 5) on estrogen-induced increases in uterine blood flow at the time of maximum response and uterine secretion of cGMP in nonpregnant sheep. Letters denote differences between groups at $P \leq 0.006$ by ANOVA. 


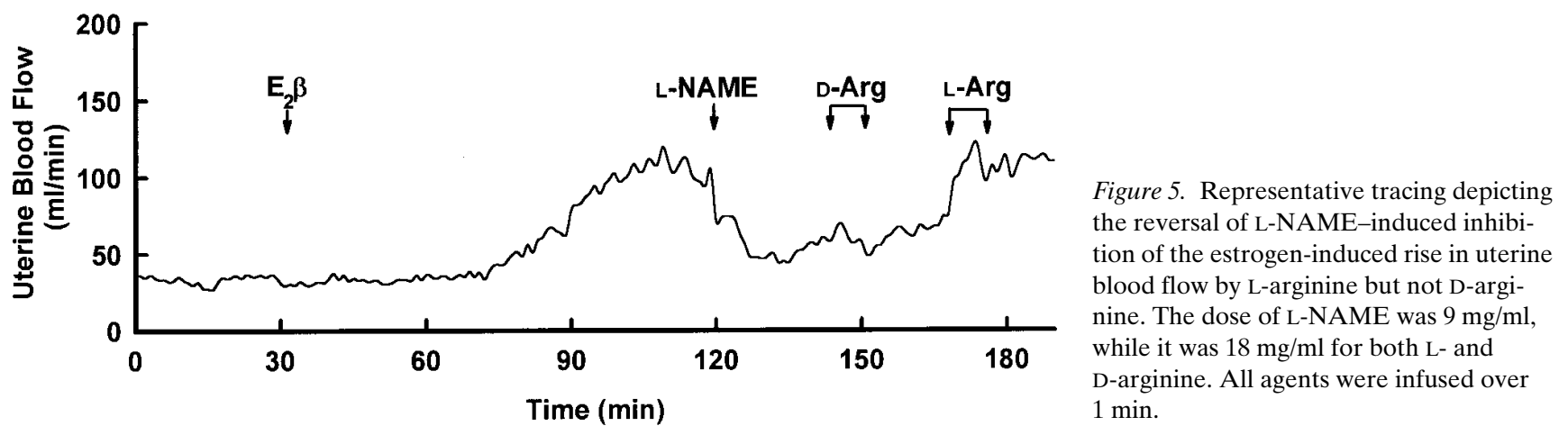

and thus production and/or secretion rates for this vascular bed, but also the local infusion of specific inhibitors to examine their effects independent of systemic responses. This animal model thus provides an excellent means of examining in vivo the mechanisms responsible for the cardiovascular effects of estrogen. We, therefore, used this model to study the effects of $\mathrm{E}_{2} \beta$ on uterine cGMP production and have correlated these observations with the $\mathrm{E}_{2} \beta$-mediated increases in UBF in nonpregnant castrated ewes. By locally infusing the NOS specific antagonist L-NAME (16), data were obtained supporting the thesis that estrogen-induced increases in uterine cGMP are mediated via NOS and contribute to the observed rise in UBF as well as its maintenance after $\mathrm{E}_{2} \beta$ treatment. Data also were obtained in pregnant sheep to support this conclusion; however, NOS inhibition did not consistently decrease basal uteroplacental perfusion, suggesting other factors may be involved with the rise in and maintenance of uteroplacental blood flow during pregnancy.

Estrogen increases UBF and cardiac output as well as decreases systemic vascular resistance in several species (4-11, $25,26)$. The uterine responses are dose dependent and have been observed with all estrogens $(4,5,27)$, including catechol

Table II. Effects of $E_{2} \beta(1 \mu \mathrm{g} / \mathrm{kg}$ i.v.) on UBF and Systemic Hemodynamic Variables in the Absence and Presence of Systemic Treatment with Indomethacin $(2 \mathrm{mg} / \mathrm{kg}$ i.v. $)$ in Nonpregnant Sheep $(n=4)$

\begin{tabular}{ccccc}
\hline Time & UBF & MAP & Cardiac output & Heart rate \\
\hline min & ml/min & $m m H g$ & liter $/$ min & $b p m$
\end{tabular}

(A) $\mathrm{E}_{2} \beta$ alone:

$\begin{array}{rclll}-30 & 43.0 \pm 13.2^{*} & 82 \pm 2^{*} & 4.28 \pm 0.41 & 79 \pm 3^{*} \\ 0 & 40.5 \pm 13.0^{*} & 83 \pm 4^{*} & 4.53 \pm 0.34 & 78 \pm 2^{*} \\ 90 & 177 \pm 28^{\ddagger} & 80 \pm 3^{*} & 5.00 \pm 0.57 & 87 \pm 1^{\ddagger} \\ 120 & 186 \pm 27^{\ddagger} & 83 \pm 3^{*} & 5.08 \pm 0.17 & 89 \pm 3^{\ddagger} \\ & & & & \\ -30 & 28.0 \pm 9.1^{*} & 87 \pm 2^{*} & 4.20 \pm 0.31^{* \ddagger} & 80 \pm 4^{*} \\ -10 & 26.8 \pm 9.5^{*} & 91 \pm 4^{*} & 3.38 \pm 0.50^{\S} & 61 \pm 4^{\ddagger} \\ 0 & 29.8 \pm 11^{*} & 87 \pm 3^{*} & 3.65 \pm 0.34^{\ddagger} & 65 \pm 5^{\ddagger} \\ 90 & 174 \pm 27^{\ddagger} & 89 \pm 4^{*} & 4.73 \pm 0.48^{* \ddagger} & 94 \pm 3^{\S} \\ 120 & 183 \pm 27^{\ddagger} & 89 \pm 3^{*} & 5.08 \pm 0.55^{*} & 98 \pm 4^{\S}\end{array}$

Values are mean \pm SEM. Different superscripts denote differences within columns at $P \leq 0.01$ by ANOVA. "The rise in cardiac output had $P=$ 0.089. Indo, indomethacin. estrogens (28); however, their potencies vary considerably, e.g., $\mathrm{E}_{2} \alpha$ requires a 10 -fold greater dose than $\mathrm{E}_{2} \beta(4,5)$. Thus vasodilation is a general response after estrogen administration. Nonetheless, not all vascular beds respond similarly $(4,8$, 9), which may reflect differences in estrogen receptor expression. Estrogen receptors are expressed in uterine artery endothelium and media (29-31); however, the $\mathrm{E}_{2} \beta$-induced rise in UBF has not been clearly shown to be mediated through the estrogen receptor. Moreover, it remains unclear whether these acute responses reflect genomic or nongenomic mechanisms. The rapidity of the responses observed in the present and previous reports, i.e., within 30 to $90 \mathrm{~min}$, suggest that they may be nongenomic. This is also supported by observations that inhibition of transcription does not alter acute $E_{2} \beta$-induced rises in UBF $(4,14,15)$. In contrast, chronic estrogen exposure results in hemodynamic responses that change with time (26), suggesting that these responses are more complex and may in part reflect genomic mechanisms. Nonetheless, new protein synthesis appears to be involved since the acute responses to estrogen are reversibly inhibited by cycloheximide $(5,32)$. Thus NOS or a related protein may be involved.

In the vasculature NO is generally derived from the endothelium via conversion of L-arginine to L-citrulline by way of type III NOS. This source of NO is believed to provide for transient modulation of vascular tone (16). It can also be derived from the type II isoform, which can be induced in vascu-

Table III. Comparison of UBF, Uterine Arterial and Venous cGMP Concentrations, and Uterine Secretion of $c G M P$ in Nonpregnant and Pregnant Ewes

\begin{tabular}{lcccc}
\hline & Nonpregnant & Pregnant & Fold $\uparrow$ \\
\hline & $n=14$ & & $n=5$ & \\
& $33 \pm 5$ & $\S$ & $602 \pm 99$ & 18.2 \\
$\begin{array}{l}\text { Uterine blood flow (ml/min) } \\
\text { cGMP (pmol/ml): }\end{array}$ & & & & \\
$\quad$ Arterial & $2.41 \pm 0.42$ & $\ddagger$ & $8.76 \pm 0.92$ & 3.65 \\
& $*$ & & $\ddagger$ & \\
$\quad$ Uterine vein & $4.10 \pm 0.88$ & $\ddagger$ & $12.8 \pm 1.22$ & 3.12 \\
$\quad$ Uterine vein-arterial] & $1.69 \pm 0.48$ & $\ddagger$ & $4.03 \pm 0.38$ & 2.38 \\
$\begin{array}{c}\text { Total uterine cGMP Secretion } \\
\text { (pmol/min) }\end{array}$ & $61 \pm 24$ & $\S$ & $2302 \pm 281$ & 37.8 \\
& & & & \\
& & & &
\end{tabular}

Values are the means \pm SEM, ${ }^{*} P<0.05 ;{ }^{\ddagger} P<0.01 ;{ }^{\S} P<0.001$. Pregnant sheep were $119 \pm 1 \mathrm{~d}$ gestation $($ term $=145 \mathrm{~d})$, five experiments in three sheep. Nonpregnant sheep, 14 experiments in 5 sheep. 
Table IV. The Effect of Local Intra-arterial Infusion of $L-N A M E(12 \pm 6 \mathrm{mg} / \mathrm{ml})$ on UBF and Uterine Secretion of cGMP $(n=5)$ in Pregnant Sheep

\begin{tabular}{lcccc}
\hline & Control & 5 min & 30 min & $P$ \\
\hline $\begin{array}{l}\text { Uterine blood } \\
\text { flow (ml/min) }\end{array}$ & $301 \pm 38^{*}$ & $265 \pm 43^{*}$ & $271 \pm 27^{*}$ & 0.76 \\
$\begin{array}{c}\text { Uterine cGMP } \\
\text { secretion (pmol/min) }\end{array}$ & $1236 \pm 212^{*}$ & $1374 \pm 291^{*}$ & $423 \pm 157^{\ddagger}$ & 0.02
\end{tabular}

Values are means \pm SEM. Superscripts denote differences between time periods.

lar smooth muscle by cytokines over $12-24 \mathrm{~h}$, resulting in a more prolonged rise in NO synthesis (16). The vasodilatory effects of NO on smooth muscle, irrespective of its source, are primarily mediated by stimulation of guanylate cyclase and enhanced cGMP production (16). Numerous investigators have demonstrated that A23187- and acetylcholine-induced relaxation, which is mediated by NO, is enhanced after estrogen exposure $(2,18,20,33-35)$; but few have measured cGMP production either in vitro or in vivo or have demonstrated a direct relaxant effect of estrogen. In the present report, acute $\mathrm{E}_{2} \beta$ exposure caused a rapid rise in uterine venous concentrations of cGMP and an increase in uterine cGMP production, both of which precede or occur concomitantly with the rise in UBF and fall in uterine vascular resistance (MAP was unchanged). If indeed it is the former, cGMP accumulation in smooth muscle may need to occur before vascular relaxation can be appreciated with the electromagnetic flow probes. Nonetheless, once cGMP production increases, it then follows a pattern of rise identical to that of UBF. This plus the highly significant linear correlation between these two events supports the thesis that the $\mathrm{E}_{2} \beta$-induced increases in cGMP may be responsible for the rise in $\mathrm{UBF}$. To determine if the rise in uterine venous cGMP reflects increases in NOS-derived NO, L-NAME, a specific NOS antagonist, was infused into the uterine artery before $\mathrm{E}_{2} \beta$. L-NAME did not affect basal UBF, which is clearly quite low, or uterine venous cGMP levels. The former may reflect the inability of the flow probes to detect small changes in UBF at such low flows. However, pretreatment completely inhibited the subsequent rise in uterine venous cGMP and cGMP production, while only partially inhibiting the $E_{2} \beta$ induced rise in UBF, demonstrating a dissociation between alterations in CGMP and UBF. These observations lead us to conclude that $E_{2} \beta$-induced increases in UBF are partially due to enhanced smooth muscle cGMP synthesis, which is reflective of either enhanced NO synthesis or increases in NOS. Alternatively, there may be decreased NO degradation or enhanced smooth muscle responsiveness to NO. Since neither L-NAME nor L-arginine appear to affect basal UBF, it is possible in the nonpregnant ewe that NO does not regulate basal uterine vascular tone or NOS activity is quite low and that NO production is not limited by availability of L-arginine (36).

As noted above, there was a dissociation between the $\mathrm{E}_{2} \beta$ induced rise in UBF and cGMP production after local L-NAME infusion. For example, even though increases in uterine venous cGMP and cGMP secretion were totally inhibited by as little as $2 \mathrm{mg} / \mathrm{ml}$, UBF rose approximately fourfold (Table I). It is notable that complete NOS inhibition occurs in vitro with 2 mmol/liter L-NAME (unpublished observations). This dissociation between cGMP production and the rise in UBF suggests that another mechanism(s) may be involved. Estrogen has been shown to stimulate endothelium-derived prostacyclin synthesis $(37,38)$; however, this observation has not been consistent $(39,40)$. In the present report, systemic administration of a potent cyclooxygenase inhibitor, using a dose shown to inhibit prostanoid synthesis in pregnant ewes $(21,22)$, had no effect on either the acute uterine or systemic responses to $E_{2} \beta$. Others have reported that estrogen may also affect smooth muscle tone or responsiveness through endothelium-independent mechanisms (41) and altered fluxes of smooth muscle calcium and/or potassium (42-47). In particular, White et al. (47) recently reported that $E_{2} \beta$ relaxes porcine coronary artery smooth muscle within 5-10 min through an endothelium-independent mechanism involving $\mathrm{K}^{+}$efflux via a calcium-dependent $\mathrm{K}^{+}$channel and a cGMP-dependent mechanism. This is quite interesting, but has not been examined in uterine artery smooth muscle; it may, however, provide an explanation for the current findings. That is, there may be rapid effects of $\mathrm{E}_{2} \beta$ on uterine artery smooth muscle via alterations in $\mathrm{K}^{+}$channel activity, resulting in hyperpolarization and vasorelaxation, which are followed by its effects on endothelium-derived NO. Studies are underway to address this.

Uterine vasodilation persists $8-12 \mathrm{~h}$ after a single bolus dose of $E_{2} \beta(4,5,11)$, but the mechanism(s) that maintains this vasodilation is also unknown. The present studies support the hypothesis that this too is partially dependent upon the stimulation and maintenance of enhanced cGMP production, which in turn is predominantly or completely mediated through NO. This is obtained from the observation that local L-NAME infusion at the time of maximum UBF rapidly decreased uterine cGMP production and UBF and this inhibition was persistent for up to $30 \mathrm{~min}$. Moreover, this inhibition of UBF and cGMP was rapidly and completely reversed by local infusion of L-arginine, the natural substrate for NOS and the antagonist of L-NAME. However, it is not clear if estrogen increases NOS protein, substrate, or necessary cofactors, or if processes distal to NO synthesis are involved. As observed earlier, while the L-NAME inhibition of cGMP production was complete, UBF did not return to baseline values even at the highest doses of L-NAME infused. Van Buren et al. (17), studying the same animal model, also observed that local infusions of L-NAME at the time of maximum $\mathrm{E}_{2} \beta$-induced UBF caused dose-dependent falls in UBF; but as in the present report, inhibition of the rise in UBF did not exceed $\sim 70 \%$. Their dose response was determined from cumulative doses of L-NAME rather than single doses; therefore, the effects and doses were actually additive since doses were $10 \mathrm{~min}$ apart and the response to L-NAME persists at least $30 \mathrm{~min}$. In contrast to the present study, they did not attempt to inhibit the $\mathrm{E}_{2} \beta$-mediated rise in UBF, nor did they demonstrate specificity of the effects of L-NAME by reversing the inhibition with L-arginine or by demonstrating alterations in local cGMP or nitrite/nitrate production. Nonetheless, both studies suggest that NO is at least partially responsible for maintaining uterine vasodilation after the response to $E_{2} \beta$. It is unclear why cGMP falls to basal values while uterine vasodilation partially persists. It is possible that once maximum vasodilation has occurred either NOS cannot be completely inhibited, our doses were not high enough, or the measurement of plasma cGMP does not truly reflect intracellular cGMP. These questions will require that measure- 
ments be made of NOS activity, NOS mRNA or protein, and contents of cGMP in uterine arteries. Alternatively, the observed dissociation between UBF and cGMP after L-NAME may reflect estrogen's effect on NO-independent mechanisms.

It has been suggested that NO may be important in maintaining systemic and uteroplacental vasodilation during pregnancy (48-51). For example, increases in urinary excretion of NO metabolites and cGMP are seen in pregnant rats $(49,50)$, and NOS activity is increased in uterine arteries from pregnant guinea pigs (48) as well as sheep (24). Furthermore, NOS expression is evident in human placental tissues $(52,53)$. Although we observed greater than threefold increases in uterine venous and arterial levels of cGMP and a 38-fold rise in uterine cGMP production in ovine pregnancy, doses of L-NAME reaching $25 \mathrm{mg} / \mathrm{ml}$ did not consistently decrease uteroplacental blood flow even though cGMP secretion fell. It is, therefore, possible that NO does not play a primary role in maintaining basal uteroplacental blood flow in pregnant ewes, and that the placental tissues $(52,53)$ are the predominant source of the rise in uterine venous cGMP during pregnancy. Uteroplacental prostaglandin synthesis is similarly enhanced during pregnancy (54); yet prostanoids are not solely responsible for maintaining uteroplacental perfusion $(21,22)$. It is possible that NO and vasodilating prostanoids are important by virtue of their ability to compensate for the loss of the other. This has not been examined. On the other hand, their increases could reflect the effects of sheer stress or changes in placental function. This, however, would not explain the progressive rise in uteroplacental blood flow throughout gestation (4). Alternatively, alterations in uterine artery smooth muscle ion channels, as noted earlier, might account for the observed vasorelaxation. Another possibility is locally derived estrogen. Since placental estrogen synthesis is substantial throughout pregnancy, local tissue concentrations probably exceed plasma levels. Exogenous estrogen increases uteroplacental blood flow $40-50 \%$ in a pattern similar to that seen in nonpregnant animals $(4,9)$. This also occurs after substrate-induced increases in endogenous placental estrogen production (4, 55-57). Although we have confirmed that $\mathrm{E}_{2} \beta$ increases UBF in pregnant ewes and have now demonstrated that, as in nonpregnant animals, this is associated with a rise in uterine venous cGMP, these data do not provide conclusive evidence that local estrogens are necessary for maintaining blood flow. This will require the use of estrogen receptor antagonists, which will not rule out nonreceptor-mediated actions, and/or aromatase inhibitors, which will inhibit local estrogen synthesis. Neither has been examined; but such studies are extremely important.

In the present report we provide data demonstrating the direct association in nonpregnant sheep between acute $E_{2} \beta$ induced vasodilation and NOS activity as demonstrated by local increases in cGMP which are completely inhibited and/or antagonized by a specific NOS inhibitor and reversed by L-arginine but not $\mathrm{D}$-arginine. This suggests that $\mathrm{NO}$ may be the only first messenger of cGMP secretion in the uterine circulation. This inhibition, however, did not completely inhibit the rise in UBF; thus, other factors may be involved with the acute vasodilating effects of estrogen. These data do not address the mechanisms responsible for responses to longterm estrogen treatment. We also have observed that like vasodilating prostanoids (54), the uteroplacental synthesis of cGMP is markedly elevated during pregnancy; however, like cyclooxygenase inhibitors $(21,22)$, NOS inhibition does not decrease uteropla- cental blood flow consistently. Thus the mechanism(s) whereby uteroplacental blood flow is maintained remains a mystery. Future studies should be directed to defining the effects of longterm estrogen exposure and whether the responses seen in the present report also involve endothelium- and/or NO-independent mechanisms.

\section{Acknowledgments}

We would like to thank Ms. Susan Battle for her help in preparing this manuscript and Daniel Millican in running the cGMP assays.

This study was supported by National Institutes of Health grants HD08783 and HL49210.

\section{References}

1. Belchetz, P.E. 1994. Hormonal treatment of postmenopausal women. $N$. Engl. J. Med. 330:1062-1071.

2. Mendelsohn, M.E., and R.H. Karas. 1994. Estrogen and the blood vessel wall. Curr. Opinion Cardiol. 9:619-626.

3. Markee, J.E. 1932. Rhythmic vascular changes. Am. J. Physiol. 100:3239.

4. Rosenfeld, C.R. 1989. The Uterine Circulation. Perinatology Press, Ithaca, NY. 312 pp.

5. Killam, A.P., C.R. Rosenfeld, F.C. Battaglia, E.L. Makowski, and G. Meschia. 1973. Effect of estrogens on the uterine blood flow of oophorectomized ewes. Am. J. Obstet. Gynecol. 115:1045-1052.

6. Greiss, F.C., and S.G. Anderson. 1970. Effect of ovarian hormones on the uterine vascular bed. Am. J. Obstet. Gynecol. 107:829-836.

7. Huckabee, W.E, C. Crenshaw, C. Curet, L. Mann, and D.H. Barron. 1970. The effect of exogenous estrogen on the blood flow and oxygen consumption of the uterus of the nonpregnant ewe. Q. J. Exp. Physiol. 55:16-24.

8. Rosenfeld, C.R., A.P. Killam, F.C. Battaglia, E.L. Makowski, and G. Meschia. 1973. Effect of estradiol-17 $\beta$ on the magnitude and distribution of uterine blood flow in nonpregnant, oophorectomized ewes. Pediatr. Res. 7:139148.

9. Rosenfeld, C.R., F.H. Morriss, Jr., F.C. Battaglia, E.L. Makowski, and G. Meschia. 1976. Effects of estradiol-17 $\beta$ on blood flow to reproductive and nonreproductive tissues in pregnant ewes. Am. J. Obstet. Gynecol. 124:618-629.

10. Magness, R.R., and C.R. Rosenfeld. 1989. Local and systemic estradiol17ß: effects on uterine and systemic vasodilation. Am. J. Physiol. 256:E536E542.

11. Clewell, W.H., S. Stys, and G. Meschia. 1980. Stimulus summation and tachyphylaxis in estrogen response in sheep. Am. J. Obstet. Gynecol. 138:485493.

12. Penotti, M., T. Nencioni, L. Gabrielli, M. Farina, E. Castiglioni, and F. Polvani. 1993. Blood flow variations in internal carotid and middle cerebral arteries induced by postmenopausal hormone replacement therapy. Am. J. Obstet. Gynecol. 169:1226-1232.

13. Pirhonen, J.P., M.H. Vuento, J.I. Makinen, and T.A. Salmi. 1993. Longterm effects of hormone replacement therapy on the uterus and uterine circulation. Am. J. Obstet. Gynecol. 168:620-623.

14. Resnik, R., F.C. Battaglia, E.L. Makowski, and G. Meschia. 1975. The effect of actinomycin D on estrogen-induced uterine blood flow. Am. J. Obstet. Gynecol. 122:273-277.

15. Penney, L.L., R.J. Frederick, and G.W. Parker. 1981. 17ß-estradiol stimulation of uterine blood flow in oophorectomized rabbits with complete inhibition of uterine ribonucleic acid synthesis. Endocrinology. 109:1672-1676.

16. Nathan, C. 1995. Nitric oxide as a secretory product of mammalian cells. FASEB J. 6:3051-3064.

17. Van Buren, G.A., D. Yang, and K.E. Clark. 1992. Estrogen-induced uterine vasodilation is antagonized by L-nitroarginine methyl ester, an inhibitor of nitric oxide synthesis. Am. J. Obstet. Gynecol. 167:828-833.

18. Gisclard, V., V.M. Miller, and P.M. Vanhoutte. 1988. Effect of $17 \beta$ estradiol on endothelium-dependent responses in the rabbit. J. Pharmacol. Exp. Ther. 244:19-22.

19. Hayashi, T., J.M. Fukuto, L.J. Ignarro, and G. Chaudhuri. 1992. Basal release of nitric oxide from aortic rings is greater in female rabbits than in male rabbits: implications for atherosclerosis. Proc. Natl. Acad. Sci. USA. 89:1125911263.

20. Bell, D.R., H.J. Rensberger, D.R. Koritnik, and A. Koshy. 1995. Estrogen pretreatment directly potentiates endothelium-dependent vasorelaxation of porcine coronary arteries. Am. J. Physiol. 258:H377-H383.

21. Naden, R.P., C.A. Iliya, B.S. Arant, Jr., N.F. Gant, Jr., and C.R. Rosenfeld. 1985. Hemodynamic effects of indomethacin in chronically-instrumented pregnant sheep. Am. J. Obstet. Gynecol. 151:484-494.

22. Magness, R.R., C.R. Rosenfeld, D.J. Faucher, and M.D. Mitchell. 1992. 
Uterine prostaglandin production during ovine pregnancy: effects of angiotensin II and indomethacin. Am. J. Physiol. 263:H188-H197.

23. Naden, R.P., N.F. Gant, Jr., and C.R. Rosenfeld. 1984. The pressor response to angiotensin II: the role of peripheral and cardiac responses in pregnant and nonpregnant sheep. Am. J. Obstet. Gynecol. 148:450-457.

24. Magness, R.R., C.R. Rosenfeld, A. Hassan, and P.W. Shaul. 1996. Endothelial vasodilator production by uterine and systemic arteries. I. Effects of ANG II on $\mathrm{PGI}_{2}$ and NO in pregnancy. Am. J. Physiol. 270:H1914-H1923.

25. Uland, K., and J.T. Parer. 1966. Effects of estrogens on the cardiovascular system of the ewe. Am. J. Obstet. Gynecol. 96:400-406.

26. Magness, R.R., C.R. Parker, Jr., and C.R. Rosenfeld. 1993. Systemic and uterine responses to chronic infusion of estradiol-17ß. Am. J. Physiol. 265: E690-E698.

27. Resnik, R., A.P. Killam, F.C. Battaglia, E.L. Makowski, and G. Meschia. 1974. The stimulation of uterine blood flow by various estrogens. Endocrinology. 94:1192-1196.

28. Rosenfeld, C.R., and G.M. Jackson. 1982. Induction and inhibition of uterine vasodilation by catechol estrogen in oophorectomized, nonpregnant ewes. Endocrinology. 110:1333-1339.

29. Leiberman, J.R., C.C.J. van Vroonhoven, I. Beckmann, T.H. van der Kwast, and H.C.S. Wallenburg. 1990. Uterine artery estrogen receptors in the nonpregnant and pregnant guinea pig. Am. J. Obstet. Gynecol. 163:1685-1688.

30. Batra, S., and S. Iosif. 1987. Nuclear estrogen receptors in human uterine arteries. Gynecol. Obstet. Invest. 24:250-255.

31. Perrot-Applanat, M., M.T. Groyer-Picard, E. Gracia, F. Lorenzo, and E. Milgrom. 1988. Immunocytochemical demonstration of estrogen and progesterone receptors in muscle cells of uterine arteries in rabbits and humans. Endocrinology. 123:1511-1519.

32. Rosenfeld, C.R., B.E. Cox, T.A. Roy, and R.R. Magness. 1995. Estradiol-17 increases uterine blood flow in nonpregnant sheep through nitric oxide and new protein synthesis. FASEB J. 9:327a. (Abstr.)

33. Bell, C. 1973. Oestrogen-induced sensitization of the uterine artery of the guinea-pig to acetylcholine. Br. J. Pharmacol. 49:595-601.

34. Bell, C., and C. Coffey. 1982. Factors influencing oestrogen-induced sensitization to acetylcholine of the guinea-pig uterine artery. J. Reprod. Fertil. 66:133-137.

35. Miller, V.M., and P.M. Vanhoutte. 1991. Progesterone and modulation of endothelium-dependent responses in canin coronary arteries. Am. J. Physiol. 261:R1022-R1027.

36. Gold, M.E., K.S. Wood, R.E. Byrns, G.M. Buga, and L.J. Ignarro. 1990. L-arginine-dependent vascular smooth muscle relaxation and cGMP formation. Am. J. Physiol. 259:H1813-H1821.

37. Chang, W. J. Nakao, H. Orimo, and S. Murota. 1980. Stimulation of prostaglandin cyclooxygenase and prostacyclin synthase activities by estradiol in rat aortic smooth muscle cells. Biochim. Biophys. Acta. 620:472-482.

38. Subbiah, M.T.R., D. Deitemeyer, R. Yunker, and L. Gallon. 1981. Effect of specific estrogens on prostaglandin synthesis in aorta and thrombocytes of female pigeons. Proc. Soc. Exp. Biol. Med. 166:300-304.

39. Steinleitner, A., F.Z. Stanczyk, J.H. Levin, G. d'Ablaing III, M.A. Vijod, V.L. Shahbazian, and R.A. Lobo. 1989. Decreased in vitro production of 6-ketoprostaglandin $\mathrm{F}_{1 \alpha}$ by uterine arteries from postmenopausal women. $\mathrm{Am}$. J. $\mathrm{Ob}$ stet. Gynecol. 161:1677-1681.

40. Muck, A.O., H. Seeger, K. Korte, P.C. Dartsch, and T.H. Lippart. 1993. Natural and synthetic estrogens and prostacyclin production in endothelial cells from umbilical cord and leg veins. Prostaglandins. 45:517-525.

41. Mugge, A., M. Riedel, M. Barton, M. Kuhn, and P.R. Lichtlen. 1993. Endothelium independent relaxation of human coronary arteries by $17 \beta$ oestradiol in vitro. Cardiovasc. Res. 27:1939-1942.

42. Jiang, C., P.M. Sarrel, D.C. Lindsay, P.A. Poole-Wilson, and P. Collins. 1991. Endothelium-independent relaxation of rabbit coronary artery by $17 \beta-$ oestradiol in vitro. Br. J. Pharmacol. 104:1033-1037.

43. Zhang, F., J.L. Ram, P.R. Standly, and J.W. Sowers. 1994. 17ß-Estradio attenuates voltage-dependent $\mathrm{Ca}^{2+}$ currents in A7r5 vascular smooth muscle cell line. Am. J. Physiol. 266:C975-C980.

44. Kostrzewska, A., T. Laudanski, and S. Batra. 1993. Effect of ovarian steroids and diethylstilbestrol on the contractile responses of the human myometrium and intramyometrial arteries. Eur. J. Pharmacol. 233:127-134.

45. Stice, S.L., S.P. Ford, J.P. Rosazza, and D.E. Van Orden. 1987. Role of 4-hydroxylated estradiol in reducing $\mathrm{Ca}^{2+}$ uptake of uterine arterial smooth muscle cells through potential-sensitive channels. Biol. Reprod. 36:361-368.

46. Shan, J., L.M. Resnick, Q. Liu, X. Wu, M. Barbagallo, and P.K.T. Pang. 1994. Vascular effects of $17 \beta$-estradiol in male Sprague-Dawley rats. Am. J. Physiol. 266:H967-H973.

47. White, R.E., D.J. Darkow, and J.L. Falvo Lang. 1995. Estrogen relaxes coronary arteries by opening $\mathrm{BK}_{\mathrm{Ca}}$ channels through a cGMP-dependent mechanism. Circ. Res. 77:936-942.

48. Weiner, C.P., I. Lizasoain, S.A. Baylis, R.G. Knowles, I.G. Charles, and S. Moncada. 1994. Induction of calcium-dependent nitric oxide synthases by sex hormones. Proc. Natl. Acad. Sci. USA. 91:5212-5216.

49. Conrad, K.P., and K.A. Vernier. 1989. Plasma level, urinary excretion, and metabolic production of cGMP during gestation in rats. Am. J. Physiol. 257:R847-R853.

50. Conrad, K.P., G.M. Joffe, H. Kruszyna, R. Kruszyna, L.G. Rochelle, R.P. Smith, J.E. Chavez, and M.D. Mosher. 1993. Identification of increased nitric oxide synthesis during pregnancy in rats. FASEB J. 7:566-571.

51. Weiner, C., E. Martinez, L.K. Zhu, A. Ghodosi, and D. Chestnut. 1989. In vitro release of endothelium- derived relaxing factor by acetylcholine is increased during the guinea pig pregnancy. Am. J. Obstet. Gynecol. 161:1599_ 1605

52. Conrad, K.P., M. Vill, P.G. McGuire, W.G. Dial, and A.K. Davis. 1993. Expression of nitric oxide synthase by syncytiotrophoblast in human placental villi. FASEB J. 7:1269-1276.

53. Myatt, L., D.E. Brockman, A.L.W. Eis, and J.S. Pollack. 1993. Immunohistochemical localization of nitric oxide synthase in the human placenta. Placenta. 14:487-495.

54. Magness, R.R., M.D. Mitchell, and C.R. Rosenfeld. 1990. Uteroplacental production of eicosanoids in ovine pregnancy. Prostaglandins. 39:75-88.

55. Pupkin, M.J., D.W. Schomberg, D.A. Nagey, and C. Crenshaw. 1975. Effect of exogenous dehydroepiandrosterone upon the fetal placental biosynthesis of estrogens and its effect upon uterine blood flow in the term pregnant ewe. Am. J. Obstet. Gynecol. 121:227-232.

56. Rosenfeld, C.R., R.J. Worley, and N. Gant, Jr. 1977. Uteroplacental blood flow and estrogen production following dehydroisoandrosterone infusion. Obstet. Gynecol. 50:304-307.

57. Rosenfeld, C.R., R.J. Worley, L. Milewich, N.F. Gant, Jr., and C.R Parker, Jr. 1980. Ovine fetoplacental sulfoconjugation and aromatization of dehydroepiandrosterone. Endocrinology. 106:1971-1979. 